\title{
Biomarkers for the detection of renal fibrosis and prediction of renal outcomes: a systematic review
}

\author{
Sherry G. Mansour ${ }^{1,2}$, Jeremy Puthumana', Steven G. Coca ${ }^{3}$, Mark Gentry ${ }^{4}$ and Chirag R. Parikh ${ }^{1,2,5^{*}}$
}

\begin{abstract}
Background: Fibrosis is the unifying pathway leading to chronic kidney disease. Identifying biomarkers of fibrosis may help predict disease progression.

Methods: We performed a systematic review to evaluate the reliability of blood and urine biomarkers in identifying fibrosis on biopsy as well as predicting renal outcomes. Using MEDLINE and EMBASE, a two-stage search strategy was implemented. Stage I identified a library of biomarkers correlating with fibrosis on biopsy. Stage II evaluated the association between biomarkers identified in stage I, and renal outcomes. Only biomarkers with moderate positive correlation with fibrosis $(r>0.40$ ) or acceptable area under the curve (AUC >0.65) advanced to stage II.

Results: Stage I identified 17 studies and 14 biomarkers. Five biomarkers met criteria to advance to stage II, but only three were independently associated with renal outcomes. Transforming growth factor $\beta$ (TGF- $\beta$ ) correlated with fibrosis $(r=0.60)$, and was associated with 1.7-3.9 times the risk of worsening renal function in 426 patients. Monocyte chemoattractant protein-1 (MCP-1) diagnosed fibrosis with AUC of 0.66 and was associated with 2.311.0 times the risk of worsening renal function in 596 patients. Matrix metalloproteinase-2 (MMP-2) correlated with fibrosis $(r=0.41)$, and was associated with 2.5 times the risk of worsening renal function.

Conclusions: Given the heterogeneity of the data due to diverse patient populations along with differing renal outcomes, a meta-analysis could not be conducted. Nonetheless we can conclude from the published data that TGF- $\beta$, MCP-1 and MMP-2 may identify patients at risk for renal fibrosis and hence worse renal outcomes.
\end{abstract}

Keywords: Fibrosis, Biomarkers, Renal biopsy, Chronic kidney disease, Renal disease progression, Outcomes

\section{Background}

Chronic kidney disease (CKD) prevalence and its associated healthcare costs continue to rise. The prevalence of CKD defined as estimated glomerular filtration rate (eGFR) less than $60 \mathrm{ml} / \mathrm{min} / 1.73 \mathrm{~m}^{2}$ has steadily increased from 1988 to 2012, affecting over 19 million Americans [1]. Medicare costs for CKD are up to $\$ 45$ billion, which is a 54\% increase between 2008 and 2012 [2]. This data highlights the immense impact of CKD on socioeconomics and public health. With this increase in CKD prevalence, biomarkers to identify and predict

\footnotetext{
*Correspondence: chirag.parikh@yale.edu

'Program of Applied Translational Research, Department of Medicine, Yale University, School of Medicine, New Haven, CT, USA

${ }^{2}$ Section of Nephrology, Yale University School of Medicine, 60 Temple

Street, Suite 6C, New Haven, CT 06510, USA

Full list of author information is available at the end of the article
}

CKD progression have been increasingly studied. There has been significant progress in biomarkers of renal injury over the past decade, with biomarkers of fibrosis recently gaining focus in the literature [3, 4]. It is important to identify and predict renal fibrosis via the use of biomarkers since tubulointerstitial fibrosis is the unifying feature in progressive renal disease irrespective of the initial insult [5]. Currently, the only clinical tool available to identify fibrosis is a kidney biopsy. However, this approach is invasive and carries certain risks, and is therefore not performed routinely $[6,7]$. Identifying biomarkers of fibrosis is indispensible to the understanding of CKD progression since they can offer vital information in a noninvasive manner. Having a reliable panel of fibrosis biomarkers also has the potential to identify a 
subgroup of at risk patients who can be targeted for future clinical trials in hopes to improve CKD outcomes.

The objectives of this systematic review are to evaluate the reliability and performance of biomarkers of fibrosis in human studies in identifying fibrosis on biopsy and for the prediction of renal outcomes.

\section{Methods}

\section{Study identification}

In consultation with a research librarian, a two-step search strategy was performed to identify relevant literature. An initial search of MEDLINE and EMBASE was undertaken followed by analysis of the text words contained in the title and abstract, and of the index terms used to describe articles. A second search, using all identified keywords and index terms, was used across included databases. Lastly, the references of all identified articles were searched for any additional studies. Studies published in the English language from January 1995 to May 2016 were considered for inclusion.

The search was comprised of two stages. Stage I was constructed to identify a library of biomarkers that positively correlated with histological findings of fibrosis on biopsy. The keywords used to conduct stage I of the systematic review included 'biological markers', 'markers', 'biomarkers', and 'fibrosis' cross-referenced with 'chronic renal insufficiency', 'kidney disease' and 'chronic kidney disease'. Stage II was aimed to evaluate the association between biomarkers in stage I and renal outcomes. To focus on the most relevant and promising biomarkers in the literature, only biomarkers with moderate positive correlation with fibrosis $(r>0.40)$ or acceptable area under the curve (AUC >0.65) were assessed in stage II. For stage II, a separate search was conducted for the selected biomarkers and cross-referenced with the following keywords: 'chronic kidney failure', 'chronic renal insufficiency', 'kidney diseases', 'kidney prognosis', 'renal prognosis', 'disease progression,' 'renal function outcome', 'long term outcome', and 'progression of renal failure'.

\section{Study selection}

Study eligibility for stage I included studies with patients of all ages, biomarkers that were measured either in blood or urine, and studies that included a renal biopsy as the gold standard to evaluate the level of fibrosis. Studies were excluded from stage I if fibrosis was not defined or assessed on biopsy or if only tissue biomarkers were used.

The inclusion criteria for stage II also included studies with patients of all ages and biomarkers that were measured in blood or urine but studies were only eligible if biomarker measurement preceded renal outcomes. Studies included in stage II had to have at least one outcome as worsening of renal function defined histologically or by a change in urinary albumin or protein excretion, serum cystatin- $C$, serum creatinine or eGFR. Studies that included patients on renal replacement therapy at enrollment or studies that only assessed tissue biomarkers were excluded from stage II. Also studies that assessed composite outcomes of renal and non-renal events without evaluating the sole association of the biomarker with the renal event were excluded. All studies included were required to have a statistically significant adjusted point estimate or AUC associating the biomarker with the specified renal outcome.

\section{Data collection and abstraction}

Data was obtained using a standardized data extraction tool. For both stages, the data extracted included details regarding the biomarker used, the type of patient population, and sample size. Specifically for stage I, we also included the grading system used to define fibrosis on kidney biopsy as well as a Pearson correlation coefficient or sensitivity, specificity and AUC when available. For stage II, the data collection included length of follow-up for each study, as well as the study's defined renal outcome and point estimate with $95 \%$ confidence interval or sensitivity, specificity and AUC if available.

\section{Quality assessment}

Two independent reviewers assessed the papers selected. The methodological validity for studies included in stage II was assessed using standards for reporting diagnostic accuracy studies (STARD) criteria [8]. Out of the 25 STARD criteria, we used the ten most relevant parameters to assess quality for this review since the studies included are mainly prognostic rather than diagnostic in nature (Additional file 1) [9]. Studies with a score $\geq 9$ were designated as 'good' quality, $7-8$ as 'fair' quality and $\leq 6$ as 'poor' quality. Any disagreements that arose between the reviewers were resolved through discussion, or if necessary, by referral to a third reviewer.

\section{Results}

The literature search for stage I identified 3681 published articles since January 1995, of which 3471 were excluded upon title and abstract review (Fig. 1). Of the remaining 210 articles, only 17 were included in stage I [10-26]. In stage II, a total of 2734 articles were identified, from which 121 were selected for full-text evaluation (Fig. 2). From these, 9 studies were eligible to be included in stage II [27-35].

\section{Stage I study characteristics}

Fourteen distinct blood and urine biomarkers were evaluated in 2378 patients across the 17 studies identified in stage I (Tables 1 and 2). The studies assessed heterogeneous patient populations, which included 


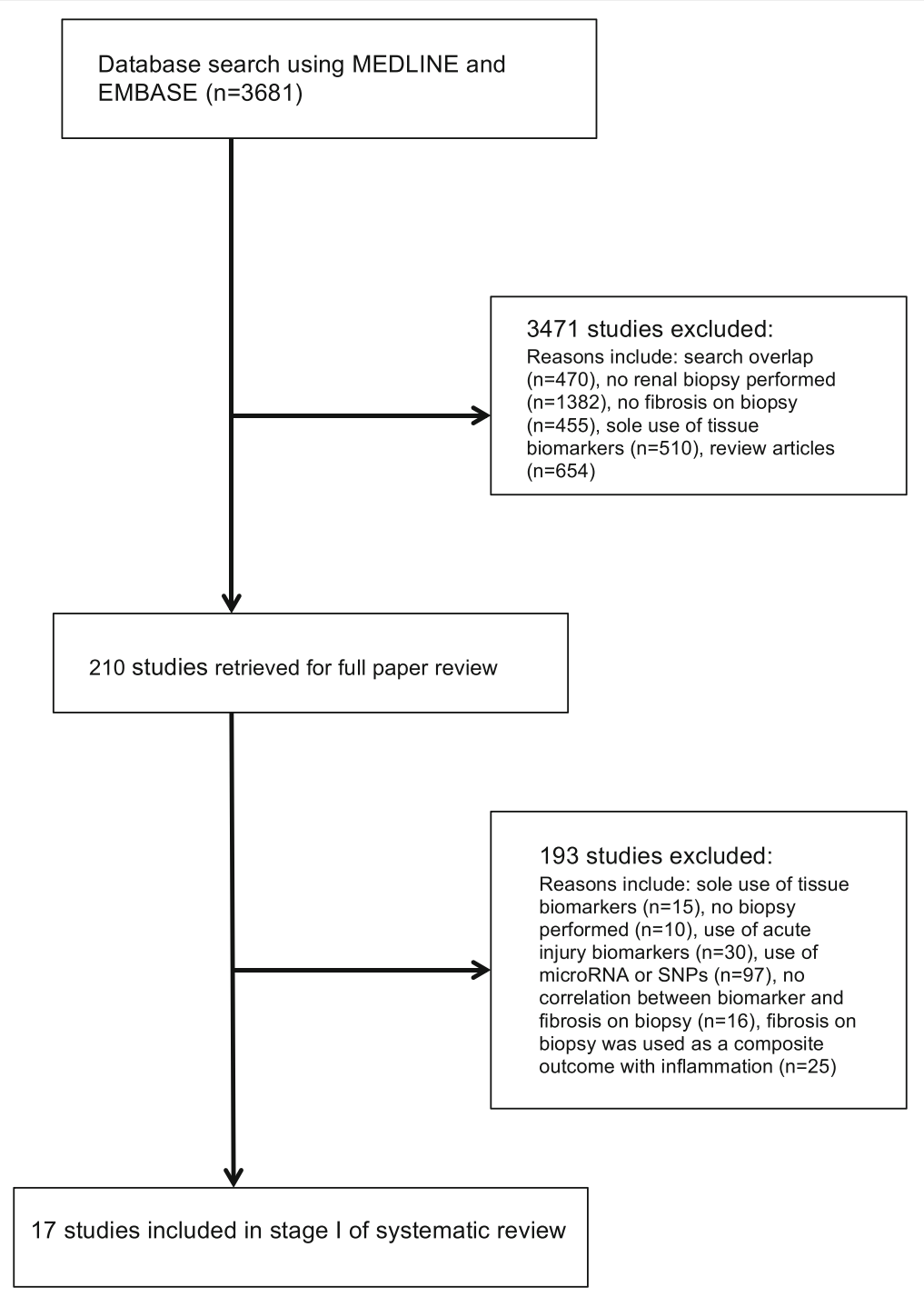

Fig. 1 Identification process for eligible studies for stage I

patients with IgA nephropathy, lupus nephritis, antineutrophil cytoplasmic antibody (ANCA) vasculitis, idiopathic membranous glomerulonephritis, and renal transplant recipients. In all studies, the biomarkers were evaluated for the primary outcome of fibrosis on biopsy. Fibrosis was evaluated by different classifications including the Oxford classification, Banff criteria, Lee's classification, image digitalization, chronic allograft damage index (CADI) score, morphometric analysis, and semi-quantitatively (Additional file 2) [36-39]. Out of the 14 biomarkers identified, only five (36\%) biomarkers had at least moderate positive correlation with fibrosis $(r>0.40)$ or acceptable AUC $>0.65$.

\section{Stage I biomarker performance (Tables 1 and 2)}

Amino-terminal propeptide of type III procollagen (PIIINP) was evaluated in three studies, encompassing a total of 237 patients with a mean age ranging from 46 to 51 years [14-16]. Overall, blood and urine PIIINP had moderate positive correlations with fibrosis on biopsy with Pearson coefficients ranging from $r=0.32$ to $r=0.51$. Using Banff 1997 criteria and semi-quantitative methods to assess fibrosis on biopsy, urine PIIINP positively correlated with fibrosis $(r=0.41, p<0.001)$ and lower levels of PIIINP predicted no fibrosis with a specificity of $84 \%$, a sensitivity of $83 \%$, and a positive predicative value (PPV) of $81 \%$ [15]. Another study used morphometric analysis to assess fibrosis and found that both urine and blood PIIINP positively correlated with fibrosis $(r=0.51, p<0.01$ and $r=0.49, p<0.01$, respectively) [16].

Transforming growth factor beta (TGF- $\beta$ ) was assessed in three studies, encompassing a total of 127 patients with mean age ranging from 30 to 43 years [20-22]. Fibrosis on biopsy was assessed semi-quantitatively in all 


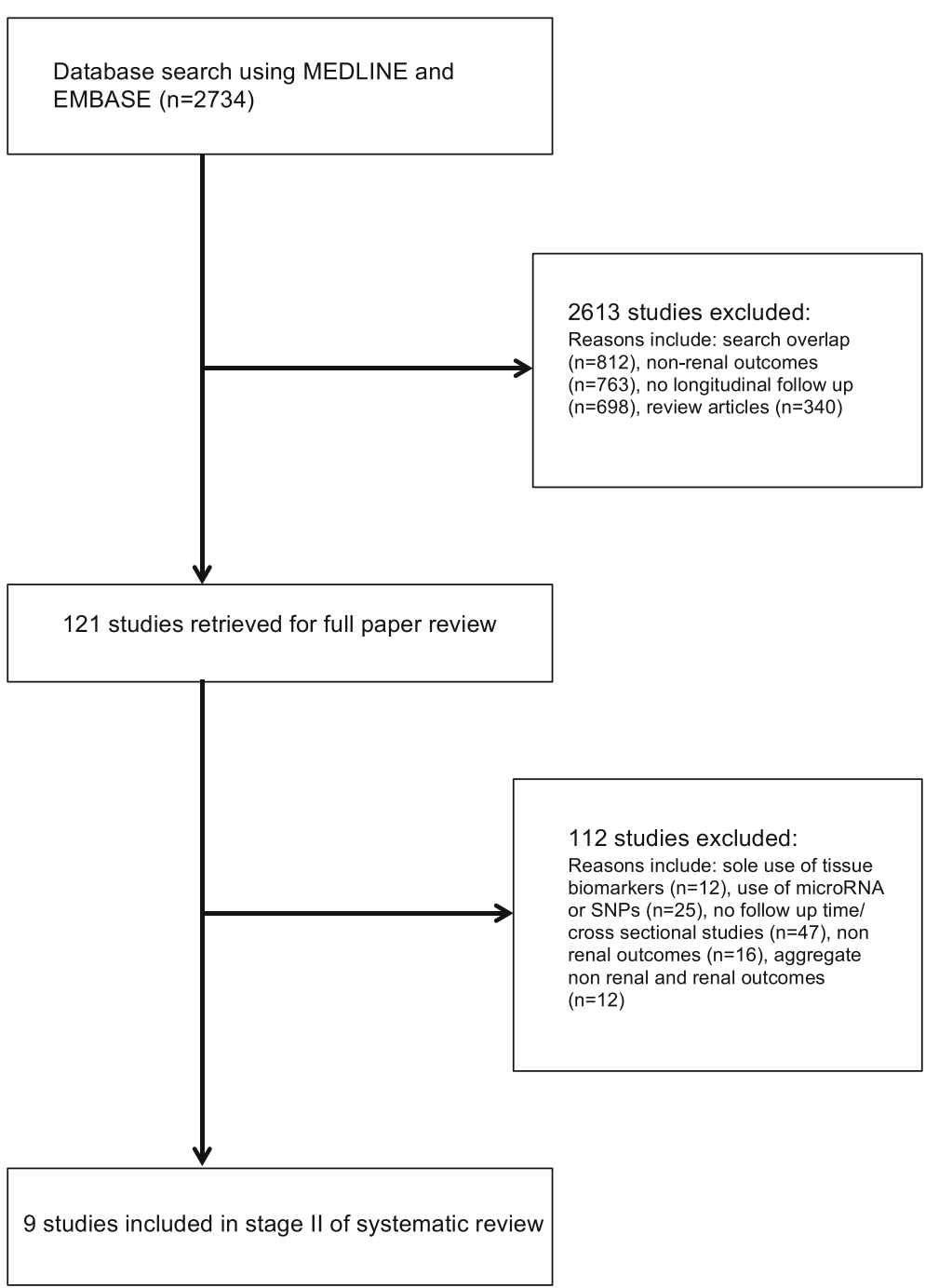

Fig. 2 Identification process for eligible studies for stage II

three studies. Urine TGF- $\beta$ positively correlated with fibrosis on biopsy $(r=0.60, p<0.001)$, and was able to diagnose fibrosis $>5 \%$ with an AUC of 0.90 [21]. Urine TGF- $\beta$ was also found to positively correlate with future fibrosis on biopsy in seven patients 1-year post biomarker measurement $(r=0.86, p=0.01)$ [20].

Monocyte chemoattractant protein (MCP-1) was evaluated in 61 patients with lupus nephritis and a median age of 30 years [24]. Biopsies were done within $24 \mathrm{~h}$ of urine biomarker measurement and fibrosis on biopsy was assessed semi-quantitatively. Urine MCP-1 was able to diagnose fibrosis on biopsy with an AUC of 0.66.

Plasminogen activator inhibitor-1 (PAI-1) was evaluated in 50 renal transplant patients with a mean age of 51 years and baseline eGFR of $32 \mathrm{ml} / \mathrm{min} / \mathrm{m}^{2}$ [25]. The CADI score was used to quantify fibrosis on biopsy. Blood PAI-1 levels positively correlated with fibrosis on biopsy $(r=0.41, p=0.003)$.
Matrix metalloproteinase-2 (MMP-2) was assessed in 29 patients with ANCA vasculitis and a median age of 67 years. Using a semi-quantitative method to measure fibrosis on biopsy, urine MMP-2 positively correlated with fibrosis on biopsy with $r=0.41$.

\section{Stage II study characteristics}

Out of the five biomarkers identified in stage I to have at least $r>0.40$ or AUC $>0.65$, only three, TGF- $\beta$, MMP- 2 , and MCP-1, were independently associated with renal outcomes over longitudinal follow-up. A total of nine articles were included in stage II (Table 3 and 4). The studies assessed different patient populations, which included patients with type II diabetes, obstructive nephropathy, those receiving coronary angiography, renal transplant patients and simultaneous pancreas and kidney transplant patients. In all studies, the biomarkers were independently associated with worsening renal function. 


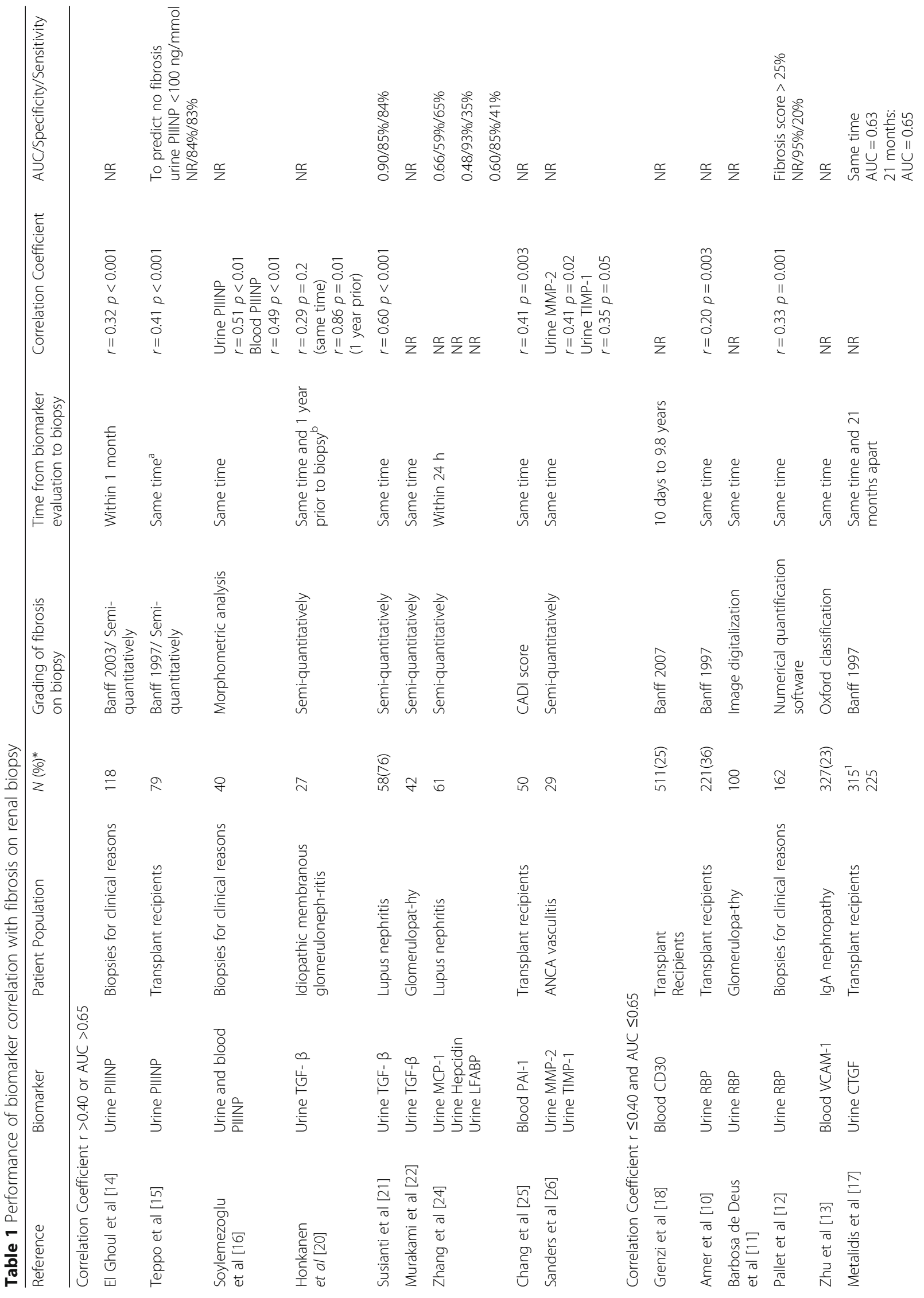




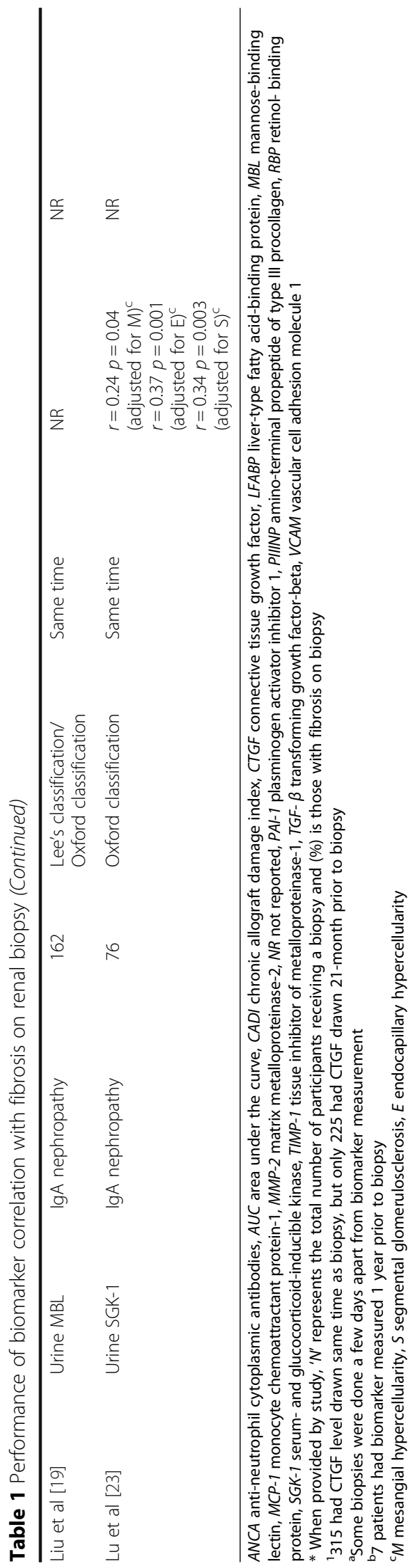


Table 2 Characteristics of studies included in stage I

\begin{tabular}{|c|c|c|c|c|c|c|}
\hline Reference & Biomarker & $\begin{array}{l}\text { Age (years) } \\
\text { Mean } \pm \text { SD } \\
\text { Median (range) }\end{array}$ & $\begin{array}{l}\text { Sex } \\
\text { (\% Male) }\end{array}$ & $\begin{array}{l}\text { Race } \\
\text { (\% Caucasian) }\end{array}$ & Method used to obtain GFR & $\begin{array}{l}\text { Baseline GFR } \\
\text { Mean } \pm \text { SD } \\
\text { Median (range) }\end{array}$ \\
\hline El Ghoul et al [14] & Urine PIIINP & $46 \pm 17$ & $48 \%$ & $88 \%$ & Four variable MDRD & $48.9(3.4-203.1)$ \\
\hline Teppo et al [15] & Urine PIIINP & $47(22-68)$ & $61 \%$ & NR & 24-h creatinine clearance & 56.2 \\
\hline $\begin{array}{l}\text { Soylemezoglu } \\
\text { et al [16] }\end{array}$ & Urine and blood PIIINP & $51 \pm 18$ & NR & NR & NR & NR \\
\hline Honkanen et al [20] & Urine TGF- $\beta$ & $43^{\mathrm{a}}$ & $65 \%$ & NR & $\begin{array}{l}\text { 51Cr-EDTA- clearance or } \\
\text { 24-h creatinine clearance }\end{array}$ & NR \\
\hline Susianti et al [21] & Urine TGF- $\beta$ & $30^{\mathrm{b}}$ & $7 \%$ & NR & NR & NR \\
\hline Murakami et al [22] & Urine TGF- $\beta$ & NR & NR & NR & NR & NR \\
\hline Zhang et al [24] & $\begin{array}{l}\text { Urine MCP-1, } \\
\text { Hepcidin, LFABP }\end{array}$ & $30(17-51)$ & $11 \%$ & $46 \%$ & NR & NR \\
\hline Chang et al [25] & Blood PAl-1 & $51^{a}$ & $10 \%$ & NR & MDRD & $31.5^{c}$ \\
\hline Sanders et al [26] & $\begin{array}{l}\text { Urine MMP-2 } \\
\text { Urine TIMP-1 }\end{array}$ & $67(23-86)$ & NR & NR & NR & NR \\
\hline Grenzi et al [18] & Blood CD30 & $35(4.8-67.1)$ & $56 \%$ & $29 \%$ & Cockgraft-gault & NR \\
\hline Amer et al [10] & Urine RBP & $52 \pm 13$ & $55 \%$ & $93 \%$ & $\begin{array}{l}\text { Four variable MDRD } \\
\text { lothalamate measurement }\end{array}$ & $\begin{array}{l}53.7 \pm 14.9 \\
57.5 \pm 17.1\end{array}$ \\
\hline $\begin{array}{l}\text { Barbosa de Deus } \\
\text { et al [11] }\end{array}$ & Urine RBP & $33 \pm 12$ & $54 \%$ & $53 \%$ & Creatinine clearance & $\begin{array}{l}73.2(33-172)^{d} \\
97.5(45-175)\end{array}$ \\
\hline Pallet et al [12] & Urine RBP & $53 \pm 18$ & $54 \%$ & $53 \%$ & MDRD & $47.4 \pm 33.3$ \\
\hline Zhu et al [13] & Blood VCAM-1 & $33 \pm 11$ & $47 \%$ & NR & NR & $85.4 \pm 30.3$ \\
\hline Metalidis et al [17] & Urine CTGF & $53 \pm 13.2$ & $61 \%$ & $N R$ & MDRD & $53.3 \pm 17.4$ \\
\hline Liu et al [19] & Urine MBL & 35 & $57 \%$ & NR & Four variable MDRD & 85.9 \\
\hline Lu et al [23] & Urine SGK-1 & $38^{\mathrm{b}}$ & $52 \%$ & NR & MDRD & $90.8 \pm 43.2$ \\
\hline
\end{tabular}

CTGF connective tissue growth factor, GFR glomerular filtration rate, $L F A B P$ liver-type fatty acid-binding protein, $M B L$ mannose-binding lectin, $M C P$-1 monocyte chemoattractant protein-1, MMP-2 matrix metalloproteinase-2, NR not reported, PAl-1 plasminogen activator inhibitor 1, PIIINP amino-terminal propeptide of type III procollagen, RBP retinol- binding protein, SD standard deviation, SGK-1 serum- and glucocorticoid-inducible kinase, TIMP-1 tissue inhibitor of metalloproteinase1, TGF- $\beta$ transforming growth factor-beta, VCAM vascular cell adhesion molecule

${ }^{a}$ This age was obtained by taking the average of the median ages

${ }^{\mathrm{b}}$ This age was obtained by taking the average of the mean ages

'This GFR represents the average of the medians

${ }^{\mathrm{d}}$ The top GFR represents patients with abnormal RBP and the bottom GFR represents patients with normal RBP

\section{Stage II biomarker performance (Table 3 and 4)}

Urine TGF- $\beta$ concentrations were evaluated in 426 patients with an average age ranging from 43 to 69 years across three different studies [29-31]. One study was 'good' quality and two were 'fair' quality. Higher TGF- $\beta$ concentrations were associated with biopsy proven chronic allograft nephropathy in transplant recipients over a 5-years follow-up, as well as worsening renal function in patients with obstructive uropathy and type II diabetes (point estimates ranging from 1.7 to 3.9 ). The addition of blood TGF- $\beta$ to conventional predictors such as age, sex, duration and severity of diabetes, eGFR and albumin/creatinine ratio in patients with baseline eGFR of $55 \mathrm{ml} / \mathrm{min} / \mathrm{m}^{2}$ increased the AUC from 0.75 to 0.96 for predicting doubling of serum creatinine over a 5years follow-up period in a nested case-control study from the ADVANCE clinical trial cohort [31].

Blood and urine MMP-2 concentrations were measured in 332 patients across two studies with a mean age ranging from 46 to 67 years [27, 28]. One study was 'good' quality and another was 'fair' quality. Studies revealed that higher MMP-2 concentrations are associated with decline in eGFR in patients with and without CKD with baseline eGFR of $34 \mathrm{ml} / \mathrm{min} / \mathrm{m}^{2}$ and $74 \mathrm{ml} / \mathrm{min} / \mathrm{m}^{2}$, respectively. In one study assessing patients' eGFR post coronary angiography over an 8 years follow up, 39 (16\%) of non-CKD and non-diabetic patients had over a $25 \%$ reduction in their eGFR from baseline [27]. Those with higher blood MMP-2 levels were 2.5 times as likely to develop decline in their eGFR compared to those with lower levels. Urine MMP-2 in another study was able to predict eGFR decline with an AUC of 0.74, with a decline of $0.1 \mathrm{ml} / \mathrm{min} / \mathrm{m}^{2}$ in eGFR for every unit increase of urine MMP-2 over a 38 month follow up [28].

Urine MCP-1 was evaluated in a total of 596 patients in four studies with a mean age ranging from 38 to 69 years [32-35]. Three studies were of 'fair' quality and one was 'poor' quality. Over a follow-up period of 2 to 


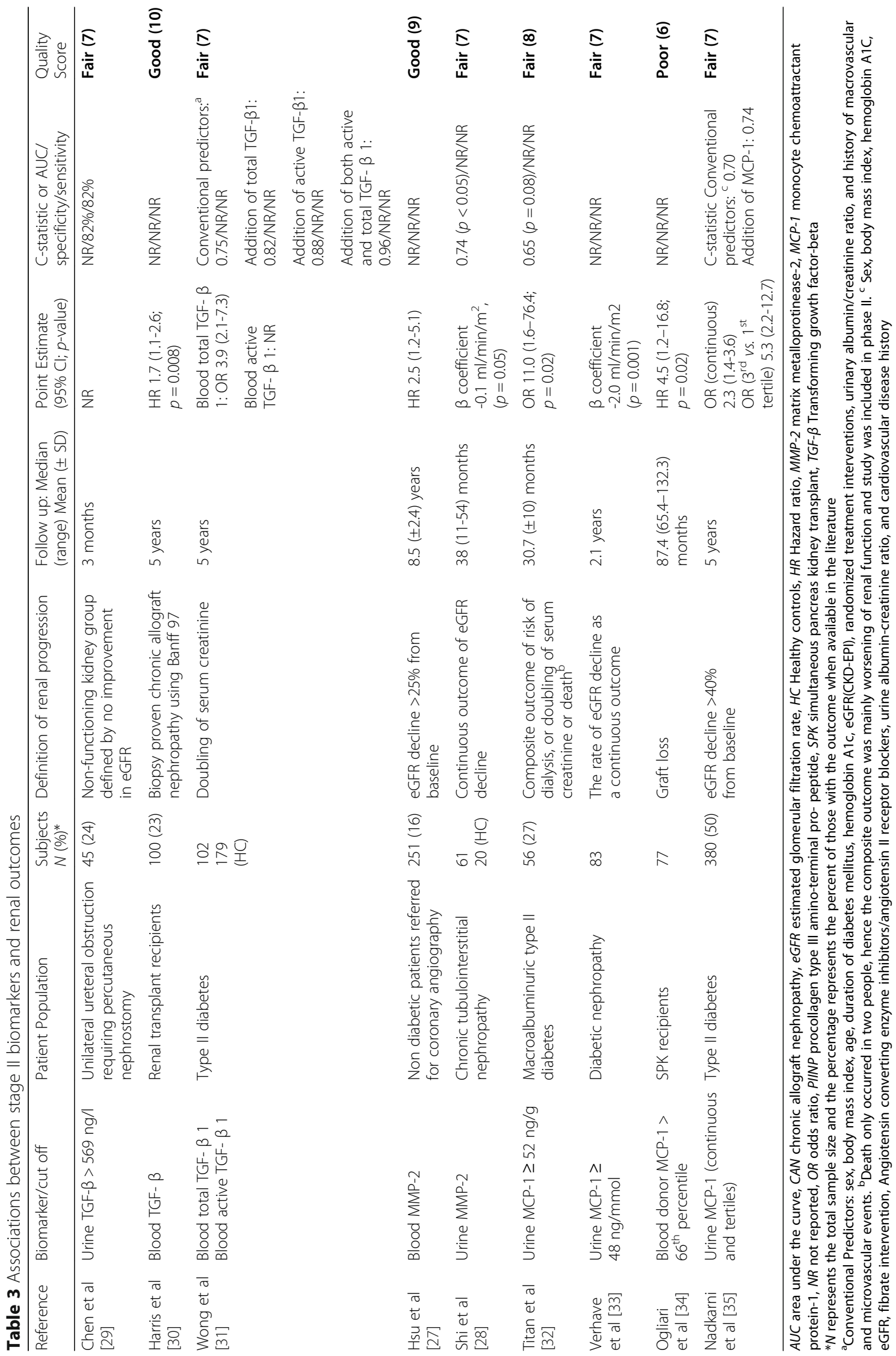


Mansour et al. BMC Nephrology (2017) 18:72

Page 9 of 13

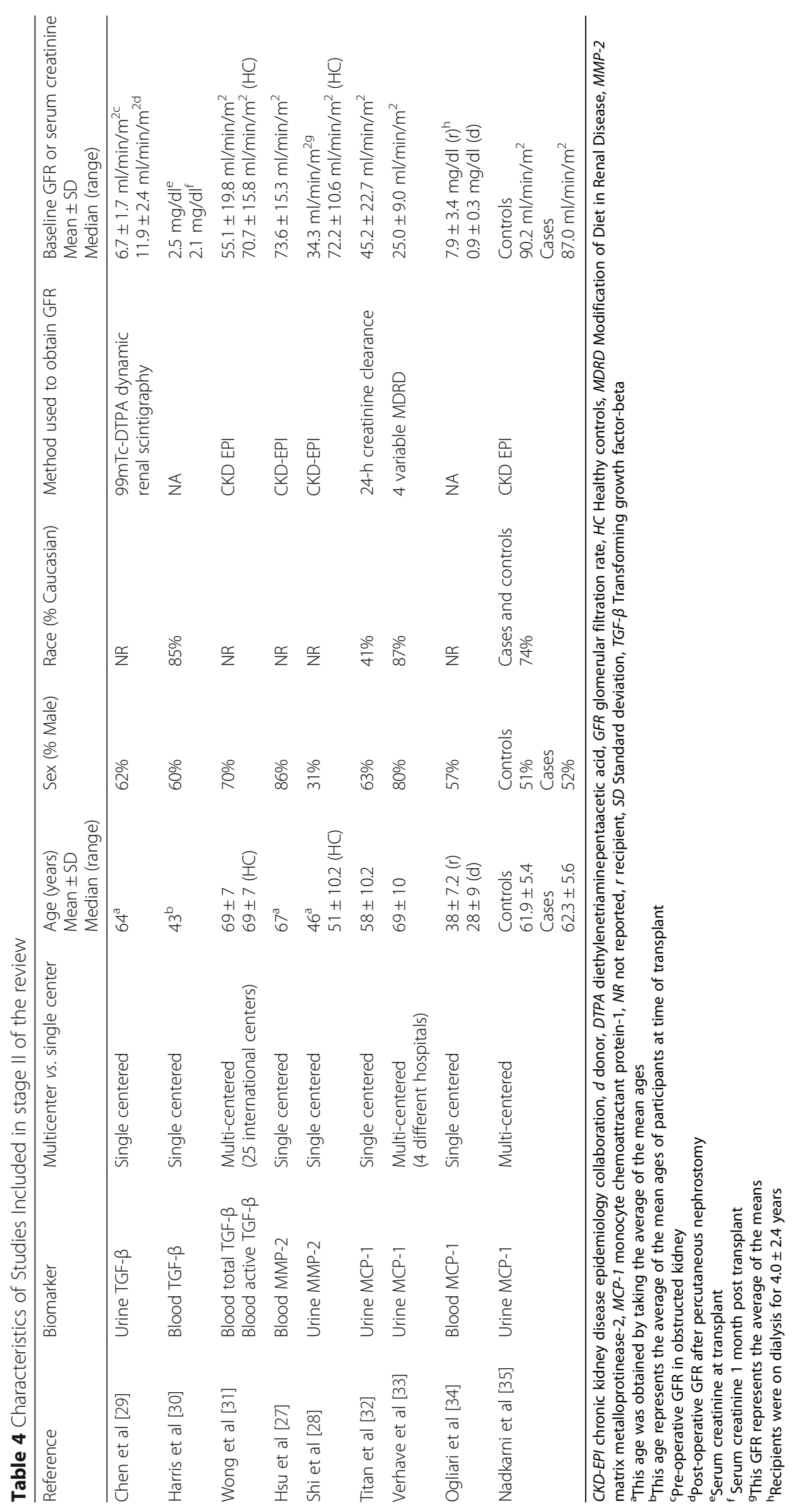


Table 5 Stage II variables used for multivariable analyses

\begin{tabular}{|c|c|c|c|}
\hline Reference & Biomarker & Patient Population & Variables used for multivariable analyses \\
\hline Chen et al [29] & Urine TGF- $\beta$ & $\begin{array}{l}\text { Unilateral ureteral obstruction } \\
\text { requiring percutaneous nephrostomy }\end{array}$ & NA \\
\hline Harris et al [30] & Blood TGF- $\beta$ & Renal transplant recipients & Acute cellular rejection \\
\hline Wong et al [31] & $\begin{array}{l}\text { Blood total and } \\
\text { active TGF- } \beta 1\end{array}$ & Type II diabetes & $\begin{array}{l}\text { Sex, age, baseline eGFR, randomized treatment interventions }{ }^{a} \text {, } \\
\text { urinary albumin/creatinine ratio, hemoglobin } A 1 c, B M l \text {, diabetes } \\
\text { duration, and history of macrovascular or microvascular disease }\end{array}$ \\
\hline Hsu et al [27] & Blood MMP-2 & $\begin{array}{l}\text { Non diabetic patients referred for } \\
\text { coronary angiography }\end{array}$ & $\begin{array}{l}\text { Age, sex, smoking status, BMI, systolic blood pressure, fasting } \\
\text { glucose, total cholesterol, and baseline eGFR }\end{array}$ \\
\hline Shi et al [28] & Urine MMP-2 & Chronic tubulointerstitial nephropathy & Age, baseline eGFR, mean blood pressure \\
\hline Titan et al [32] & Urine MCP-1 & Macroalbuminuric type II diabetes & $\begin{array}{l}\text { Baseline creatinine clearance, baseline } 24 \text { h proteinuria, } \\
\text { and systolic blood pressure }\end{array}$ \\
\hline Verhave et al [33] & Urine MCP-1 & Diabetic nephropathy & Proteinuria, TGF-B \\
\hline Ogliari et al [34] & Blood MCP-1 & SPK recipients & $\begin{array}{l}\text { Hemoglobin } A 1 c \text {, years of dialysis pre transplant, } \\
\text { recipient } B M I \text {, enteric drainage, }>1 \text { episode of } \\
\text { rejection, type of immunosuppression }\end{array}$ \\
\hline Nadkarni et al [35] & Urine MCP-1 & Type II diabetes & $\begin{array}{l}\text { Hemoglobin A1c, mean arterial pressure, history of cardiovascular } \\
\text { disease, intensive glycemic and blood pressure control, fibrates, } \\
\text { angiotensin receptor blockers, angiotensin converting enzyme } \\
\text { inhibitors, thiazolidinedione, baseline eGFR, urinary } \\
\text { albumin-creatinine ratio. }\end{array}$ \\
\hline
\end{tabular}

BMI Basic metabolic panel, eGFR estimated glomerular filtration rate, HC Healthy controls, HR Hazard ratio, MMP-2 matrix metalloprotinease-2, MCP-1 monocyte chemoattractant protein-1, NA not applicable, SPK simultaneous pancreas kidney transplant, TGF- $\beta$ Transforming growth factor-beta

${ }^{a}$ Wong et al was an ancillary study from the ADVANCE trial cohort, which randomized participants to intensive glucose control, targeting a hemoglobin A1c of $\leq 6.5 \%$, or to standard, guideline-based glucose control, as well as to combination perindopril-indapamide therapy or to matching placebo

7 years, higher levels of urine and blood MCP-1 were significantly and independently associated with future eGFR decline and doubling of creatinine in native kidneys and graft loss in transplant recipients with baseline eGFR ranging from $25 \mathrm{ml} / \mathrm{min} / \mathrm{m}^{2}$ to $90 \mathrm{ml} / \mathrm{min} / \mathrm{m}^{2}$ (point estimates ranging from 2.3 to 11.0 ).

\section{Discussion}

The relentless progression of renal disease is closely linked to the process of fibrosis, which is triggered by initial or ongoing injury. Although it is still a point of debate, there is literature to support a mechanistic rather than merely an associative role of fibrosis in progression of kidney disease [40]. This systematic review is a comprehensive evaluation of renal biomarkers that can be used in the detection of fibrosis as well as in the prediction of progression of renal disease. However, the development of a clinically useful biomarker is a sequential process that usually requires five phases; phase 1 identifies promising directions in preclinical studies, phase 2 is clinical assay validation and detection of established disease, phase 3 is biomarker prediction of clinical disease in longitudinal studies, phase 4 is prospective screening and finally phase 5 is impact of screening on disease burden [41]. This systematic review aimed to identify fibrosis biomarkers that achieved phase 2 and phase 3 of development. A total of 14 biomarkers were identified in phase 2 of development and were linked to fibrosis on biopsy, but the majority (64\%) had weak correlations or unreported associations in the literature. Only five biomarkers (PAI-1, PIIINP, MMP-2, TGF- $\beta$, and MCP-1) had at least moderate correlations with fibrosis on biopsy, out of which only three (MMP-2, TGF- $\beta$, and MCP-1) were independently associated with worsening renal function.

TGF- $\beta$ had the strongest correlation with fibrosis on biopsy and was significantly associated with worse renal outcomes in the literature. This is supported by strong biological plausibility in animal literature, where the overexpression of TGF- $\beta$ by renal tubular epithelial cells led to tubulointerstitial fibrosis and the blocking of TGF- $\beta$ ameliorated this process $[42,43]$. In this review, MCP-1 had a very strong association with progression of renal disease, which is reinforced by preclinical studies showing that the blockade of MCP-1 receptor (CCR2) reduces interstitial fibrosis [44]. Lastly, MMP-2 was also a strong independent predictor of declining eGFR, which is again corroborated by decreased fibrosis in MMP-2 knockout mice [45].

However, this systematic review highlights the limitations in the available literature assessing fibrosis biomarkers. First, all three biomarkers were evaluated in both blood and urine in stage II studies but were only evaluated in urine in stage I studies. This highlights the need for further studies evaluating the correlation of blood levels of these biomarkers and fibrosis on biopsy. Also, generalizability to all patients is limited as most studies in both stages I and II evaluated specific patient 
populations such as lupus nephritis or IgA nephropathy. Biomarker performance differed across different patient populations, which further hinders the application to a broad patient population.

Statistical deficiencies also existed among studies. In stage I, five out of 17 studies did not report estimates of diagnostic accuracy or measures of statistical uncertainty (Table 1). Only three studies reported AUC values for diagnosing the presence and the severity of fibrosis. Lastly, stage I studies lacked a standard method to assess fibrosis with up to eight different classifications utilized (Additional file 2). This heterogeneity in the assessment of fibrosis makes it difficult to make standardized comparisons among biomarkers of fibrosis across studies.

Using the adjusted STARD quality score to assess stage II studies, only two out of nine studies were of good quality, highlighting potential areas of improvement. The majority of studies utilized convenience sampling, which introduces 'selection bias' as the participant sampling might not be an accurate representation of the population. Only one out of the nine studies in stage II stated that the examiners of the index test and reference standard were blinded. Lack of blinding could have introduced 'review bias', as the reviewers were aware of the reference test result. The adjustment for confounding was also limited in most stage II studies lacking the current clinical gold standard to assess patient outcomes, which is the use of baseline eGFR and proteinuria (Table 5). Lastly, PAI-1 and PIIINP studies performed well in stage I, but were not included in stage II secondary to lack of longitudinal studies and lack of independent association with CKD progression after adjusting for eGFR and proteinuria, respectively [46].

We also acknowledge some of the limitations to our approach. We allowed for the liberal inclusion of all patient populations as well as a wide spectrum of renal outcomes to be able to capture the maximum number of biomarkers of fibrosis assessed in the literature. However, this approach led to heterogeneity in the data and did not allow the summation of the results into a meta-analysis (Additional file 3). In addition, our two-stage approach allowed for the selection of biomarkers that both correlated with fibrosis on biopsy and were associated with renal outcomes. Hence, only biomarkers that were both diagnostic of fibrosis and predictive of outcomes were included in this systematic review. The purpose of this design was to specifically identify biomarkers of fibrosis rather than the general identification of biomarkers of progression, but this would undervalue a good predictive biomarker that has not yet been studied in biopsy confirmed renal fibrosis.

\section{Conclusion}

Despite the above limitations, there are promising considerations that are highlighted in this review. This review identifies gaps in the literature in the field of renal fibrosis and emphasizes the need for additional studies utilizing biopsies to identify subclinical fibrosis. Furthermore, three promising biomarkers are featured in this review to have diagnostic and prognostic potential in patients with renal disease. MMP-2, MCP- 1 and TGF- $\beta$ have been shown to identify patients with fibrosis and future poor renal outcomes. Since biomarkers of fibrosis have the potential to identify at risk populations as well as offer insight into possible therapeutic measures, it is imperative for future studies to evaluate the role of these biomarkers in diagnosing established interstitial fibrosis as well as evaluating their associations with future renal outcomes.

\section{Additional files}

Additional file 1: Study quality scoring system for stage II. Out of the 25 standards for reporting diagnostic accuracy studies (STARD) criteria, we used the ten most relevant parameters to assess quality of studies listed in this review. Studies meeting each criterion are listed under comments on the far right of the table. (DOCX $14 \mathrm{~kb}$ )

Additional file 2: Methods of fibrosis assessment on biopsy in stage studies. The table above shows the different methods used to assess fibrosis across different studies in stage I. Fibrosis was evaluated using Banff criteria, image digitalization, numerical quantification score, Oxford classification, morphometric analysis, Lee's classification, chronic allograft damage index (CADI) score, and semi-quantitatively. (DOC $31 \mathrm{~kb}$ )

Additional file 3: Patient populations and renal outcomes assessed in stage I and stage II of the systematic review. The above table shows the heterogeneity in the data with varying patient populations and different operational definitions of worsening renal function. (DOC $43 \mathrm{~kb}$ )

\section{Abbreviations}

ANCA: Anti-neutrophil cytoplasmic antibody; AUC: Area under the curve; CADI: Chronic allograft damage index; CCR2: MCP-1 receptor; CKD: Chronic kidney disease; eGFR: Estimated glomerular filtration rate; MCP-1: Monocyte chemoattractant protein-1; MMP-2: Matrix metalloproteinase-2; PAI-1: Plasminogen activator inhibitor-1; PIIINP: Amino-terminal propeptide of type III procollagen; STARD: Standards for reporting diagnostic accuracy studies; TG F- $\beta$ : Transforming growth factor beta

\section{Acknowledgements}

The authors wish to thank West Haven Veterans Affairs Medical Center (VAMC) for their support.

\section{Funding}

Not applicable.

\section{Availability of data and materials}

All data generated or analyzed during this study are included in this published article [and its supplementary information files].

\section{Authors' contributions}

SM contributed to study design, literature search, data abstraction, quality assessment and writing of manuscript. JP contributed to study design, quality assessment and writing of manuscript. SC contributed to study design, and writing of manuscript. MG contributed to study design, and literature search. CP contributed to study design, data abstraction, and writing of manuscript. All authors read and approved the final manuscript. 


\section{Competing interests}

The authors declare that they have no competing interests.

\section{Consent for publication}

Not applicable.

\section{Ethics approval and consent to participate}

Not applicable.

\section{Author details}

${ }^{1}$ Program of Applied Translational Research, Department of Medicine, Yale University, School of Medicine, New Haven, CT, USA. ${ }^{2}$ Section of Nephrology, Yale University School of Medicine, 60 Temple Street, Suite 6C, New Haven, CT 06510, USA. ${ }^{3}$ Department of Medicine, Division of Nephrology, Icahn School of Medicine at Mount Sinai, New York, NY, USA. ${ }^{4}$ Harvey Cushing/ John Hay Whitney Medical Library, Yale University, New Haven, CT, USA. ${ }^{5}$ Veterans Affairs Connecticut Healthcare System, New Haven, CT, USA.

Received: 11 September 2016 Accepted: 14 February 2017 Published online: 20 February 2017

\section{References}

1. USRDS. CKD in the general population. In: Atlas of CKD \& ESRD, Vol 1, Chapter 1. Ann Arbor, MI, USA: USRDS; 2014. p. 15.

2. USRDS. Medicare expenditures for CKD. In: Atlas of CKD \& ESRD, Vol 1, Chapter 6. Ann Arbor, MI, USA: USRDS; 2014. p. 58-62.

3. Parikh CR, Coca SG, Thiessen-Philbrook H, Shilpak MG, Koyner JL, Wang Z, et al. Postoperative biomarkers predict acute kidney injury and poor outcomes after adult cardiac surgery. J Am Soc Nephrol. 2011;22:1748-57.

4. Parikh CR, Thiessen-Philbrook H, Garg AX, Kadiyala D, Shilpak MG, Koyner JL, et al. Performance of kidney injury molecule-1 and liver fatty acid-binding protein and combined biomarkers of AKI after cardiac surgery. Clin J Am Soc Nephrol. 2013;8:1079-88.

5. Strutz FF. Novel aspects of renal fibrogenesis. Nephrol Dial Transplant. 1995; 10:1526-32.

6. Manno C, Strippoli GF, Arnesano L, Bonifati C, Campobasso N, Gesualdo L, et al. Predictors of bleeding complications in percutaneous ultrasoundguided renal biopsy. Kidney Int. 2004;66:1570-7.

7. Shidham GB, Siddiqi N, Beres JA, Logan B, Nagaraja HN, Shidham SG, et al. Clinical risk factors associated with bleeding after native kidney biopsy. Nephrology. 2005;10:305-10.

8. Bossuyt PM, Reitsma JB, Burns DE, Gatsonis CA, Glasziou PP, Irwing LM, et al. The STARD statement for reporting studies of diagnostic accuracy: explanation and elaboration. Ann Intern Med. 2003;138(1):W1-12. doi:10.7326/0003-4819-138-1-200301070-00012-w1.

9. Bhangoo RS, Hall IE, Reese PP, Parikh CR. Deceased-donor kidney perfusate and urine biomarkers for kidney allograft outcomes: a systematic review. Nephrol Dial Transplant. 2012;27:3305-14.

10. Amer $H$, Lieske JC, Rule AD, Kremers WK, Larson TS, Franco Palacios CR, et al. Urine high and low molecular weight proteins one-year post-kidney transplant: relationship to histology and graft survival. Am J Transplant. 2013;13:676-84.

11. Barbosa de Deus R, Teixeira VPC, Kirsztajn GM. Relative contribution of morphometric and functional indicators of tubulointerstitial lesion to glomerular diseases prognosis. Nephron Clin Pract. 2008;110:164-71.

12. Pallet N, Chauvet S, Chasse JF, Vincetn M, Avillach P, Levi C, et al. Urinary retinol binding protein is a marker of the extent of interstitial kidney fibrosis. PLoS One. 2014;9:e84708. doi:10.1371/journal.pone.0084708.

13. Zhu L, Shi S, Liu L, LV J, Zhang H. Increased plasma SVCAM-1 is associated with severity in IgA nephropathy. BMC Nephrol. 2013;14:21-7.

14. El Ghoul B, Squalli T, Servais A, Elie C, Meas-Yedid V, Trivint C, et al. Urinary procollagen III aminoterminal propeptide (PIIINP): a fibrotest for the nephrologist. Clin J Am Soc Nephrol. 2010;5:205-10.

15. Teppo AM, Tornroth T, Honkanen E, Gronhagen-Riska C. Urinary aminoterminal propeptide of type III procollagen (PIIINP) as a marker of interstitial fibrosis in renal transplant recipients. Transplantation. 2002:75:2113-9.

16. Soylemezoglu O, Wild G, Dalley AJ, MacNeil S, Milford-Ward A, Brown CB, et al. Urinary and serum type III collagen: markers of renal fibrosis. Nephrol Dial Transplant. 1997;12:1883-9.
17. Metalidis C, Van Vuuren SH, Broekhuizen R, Lerut E, Naesens M, Bakker SJL, et al. Urinary connective tissue growth factor is associated with human renal allograft fibrogenesis. Transplantation. 2013;96:494-500.

18. Grenzi PC, Campos EF, Tedesco-Silva H, Felipe CR, Franco MF, Soares MF, et al. Association of high post-transplant soluble CD30 serum levels with chronic allograft nephropathy. Transplant. 2013;29:34-8.

19. Liu L, Jiang Y, Wang LN, Liu N. Urinary mannose-binding lectin is a biomarker for predicting the progression of immunoglobulin (lg)A nephropathy. Clin Exp Immunol. 2012;169:148-55.

20. Honkanen E, Teppo AM, Tornroth T, Groop PH, Gronhagen-Riska C. Urinary transforming growth factor- $\beta 1$ in membranous glomerulonephritis. Nephrol Dial Transplant. 1997;12:2562-8.

21. Susianti H, Handono K, Gunawan A, Mintaroem K, Purnomo BB, Kalim H. Transforming growth factor $\beta 1$ is better than a smooth muscle actin for the prediction of renal fibrosis in patients with nephritic lupus. Biomarkers Genomic Med. 2015;7:25-30.

22. Murakami K, Takemura T, Hino S, Yoshioka K. Urinary transforming growth factor- $\beta$ in patients with glomerular diseases. Pediatr Nephrol. 1997;11:334-6.

23. Lu X, Li M, Zhou L, Jiang $H$, Wang $H$, Chen J. Urinary serum- and glucocorticoid-inducible kinase SGK1 reflects renal injury in patients with immunoglobulin a nephropathy. Nephrology. 2014;19:307-17.

24. Zhang X, Nagaraja HN, Nadasdy T, Song H, McKinley A, Prosek J, et al. A composite urine biomarker reflects interstitial inflammation in lupus nephritis kidney biopsies. Kidney Int. 2012;81:401-6.

25. Chang HR, Yang SF, Lian JD, Lin CC, Wen MC, Chen YT, et al. Prediction of chronic allograft damage index of renal allografts using serum level of plasminogen activator inhibitor-1. Clin Transplant. 2009;23:206-12.

26. Sanders JSF, Huitema MG, Hanemaaijer R, van Goor H, Kallenberg CGM, Stegeman CA. Urinary matrix metalloproteinases reflect renal damage in anti-neutrophil cytoplasm autoantibody-associated vasculitis. Am J Physiol Renal Physiol. 2007;293:1927-34.

27. Hsu TW, Kuo KL, Hung SC, Huang PH, Chen JW, Tarng DC. Progression of kidney disease in non-diabetic patients with coronary artery disease: predictive role of circulating matric metalloproteinase-2, -3, and -9. PLoS One. 2013;8:e70132. doi:10.1371/journal.pone.0070132.

28. Shi Y, Su T, Qu L, Wang C, Li X, Yang L. Evaluation of urinary biomarkers for the prognosis of drug-associated chronic tubulointerstitial nephritis. Am J Med Sci. 2013:346:283-8.

29. Chen X, Zhu W, Al-Hayek S, Yan X, Jiang C, Zheng X, et al. Urinary TGF-1 has supplementary value in predicting renal recovery post unilateral ureteral obstruction. Int Urol Nephrol. 2015;47:33-7.

30. Harris S, Coupes BM, Roberts SA, Roberts ISD, Short CD, Brenchley PEC. TGF$\beta 1$ in chronic allograft nephropathy following renal transplantation. J Nephrol. 2007;20:177-85

31. Wong MG, Perkovic V, Woodward M, Chalmers J, Li Q, Hillis GS, Azari DY, et al. Circulating bone morphogenetic protein-7 and transforming growth factor- $\beta 1$ are better predictors of renal end points in patients with type 2 diabetes mellitus. Kidney Int. 2013;83:278-84.

32. Titan SM, Vieira Jr JM, Dominguez WV, Moreira SRS, Pereira AB, Barros RT, et al. Urinary MCP-1 and RBP: independent predictors of renal outcome in macroalbuminuric diabetic nephropathy. J Diabetes Complications. 2012; 26:546-53.

33. Verhave J, Bouchard J, Goupil R, Pichette V, Brachemi S, Madore F, et al. Clinical value of inflammatory urinary biomarkers in overt diabetic nephropathy: a prospective study. Diabetes Res Clin Pract. 2013;101:333-40.

34. Ogliari AC, Caldara R, Socci C, Sordi V, Cagni N, Moretti MP, et al. High levels of donor CCL2/MCP-1 predict graft-related complications and poor graft survival after kidney-pancreas transplantation. Am J Transplant. 2008;8:1303-11.

35. Nadkarni GN, Rao V, Ismail-Beigi F, Fonseca VA, Shah SV, Simonson S, et al. Association of urinary biomarkers of inflammation, injury, and fibrosis with renal function decline: The ACCORD trial. Clin J Am Soc Nephrol. 2016;11(8): 1343-52. doi:10.2215/CJN.12051115.

36. Cattran DC, Coppo R, Cook HT, Feehally J, Roberts ISD, Troyanov S, et al. The Oxford classification of IgA nephropathy: rationale, clinicopathological correlations, and classification. Kidney Int. 2009;76:534-45.

37. Solez K, Colvin RB, Racusen LC, Haas M, Sis B, Mengel M, et al. Banff 07 classification of renal allograft pathology: updates and future directions. Am J Transplant. 2008:8:753-60.

38. Lee HS, Lee MS, Lee SM, Lee SY, Lee ES, Leev EY, et al. Histological grading of IgA nephropathy predicting renal outcome: revisiting $H$. S. Lee's glomerular grading system. Nephrol Dial Transplant. 2005;20:342-8. 
39. Kahu J, Kyllönen L, Räisänen-Sokolowski A, Salmela K. Donor risk score and baseline biopsy CADI value predict kidney graft outcome. Clin Transplant. 2011;25:276-83

40. Cohen EP. Fibrosis causes progressive kidney failure. Med Hypotheses. 1995; 45:459-62.

41. Pepe MS, Etzioni R, Feng Z, Potter JD, Thompson ML, Thornquist M, et al. Phases of biomarker development for early detection of cancer. J Nat Cancer Inst. 2001;93:1054-61.

42. Koesters R, Kaissling B, Lehir M, Picard N, Theilig F, Gebhardt R, et al. Tubular overexpression of transforming growth factor- beta1 induces autophagy and fibrosis but not mesenchymal transition of renal epithelial cells. Am J Pathol. 2010;177:632-43.

43. Miyajima A, Chen J, Lawrence C, Ledbetter S, Soslow RA, Stern J, et al. Antibody to transforming growth factor-beta ameliorates tubular apoptosis in unilateral ureteral obstruction. Kidney Int. 2000;58:2301-13.

44. Kitagawa K, Wada T, Furuichi K, Hashimoto H, Ishiwata Y, Asano M, et al. Blockade of CCR2 ameliorates progressive fibrosis in kidney. Am J Pathol. 2004;165:237-46.

45. Du X, Shimizu A, Masuda Y, Kuwahara N, Arai T, Kataoka M, et al. Involvement of matrix metalloproteinase-2 in the development of renal interstitial fibrosis in mouse obstructive nephropathy. Lab Invest. 2012;92: 1149-60.

46. Ix J, Biggs ML, Mukamal K, Djousse L, Siscovick D, Tracy R, et al. Urine collagen fragments and CKD progression- the cardiovascular health study. J Am Soc Nephrol. 2015;26:2494-503.

\section{Submit your next manuscript to BioMed Central} and we will help you at every step:

- We accept pre-submission inquiries

- Our selector tool helps you to find the most relevant journal

- We provide round the clock customer support

- Convenient online submission

- Thorough peer review

- Inclusion in PubMed and all major indexing services

- Maximum visibility for your research

Submit your manuscript at www.biomedcentral.com/submit 